\title{
The Land and Seed Traditional Theory of Health
}

\author{
J Jainarinesingh
}

\section{INTRODUCTION}

The 'land and seed' theory hinges on the principles and practice of Ayurvedic medicine which postulates that, "if you are strong enough, cancer does not stand a chance". The theory expounds that the human body is the 'land' and all the cancercausing pathogens are the 'seed.'

The theory further expands that if a seed is strong and the land is infertile, but the environment is supportive to cancer, the disease might probably stand a chance of attacking the body. An easy and accessible defence is to minimize your environmental risks $e g$ do not smoke, avoid situations of second-hand smoke and maintain a healthy lifestyle to ward off the ravages of cancer.

A worse-case scenario would be where the seed is good - the risks of cancer are high with perhaps free radicals - the land is rich and fertile ie you do not have effective immunity to disease, and the environment supports the prevalence of disease. This may become a reality if you reside on top of a toxic waste dump in which case you run a high risk of being affected by pathogens. Fortunately, Ayurveda presents a remedy or a prescription that assists in creating 'infertile land' ie a body that is so strong that it will not support the invasion of cancer (1).

Keywords: Ayurvedic medicine, flavonoids, land, phytochemicals, seed

\section{West Indian Med J 2014; 63 (1): 88}

\begin{abstract}
AN APPLE A DAY
One step in the pathway of that remedy or prescription is a stewed apple to begin the day. Of course, there are other remedies such as other fibre-containing foods but this stewed apple helps to build the body's defences. One may wonder about the benefits of fibre in the daily diet, indeed, fibre should be a major constituent of our daily diet and the good news is that apples are loaded with pectin which is a soluble fibre that fortifies our bodies against various diseases. Apples also contain insoluble fibres which clean out the intestinal tract and keep it disease-free. Simply stated, these fibres help to create the
\end{abstract}

From: Chase Village, Chaguanas, Trinidad and Tobago.

Correspondence: Dr J Jainarinesingh, LP 61, John Elie Road, Chase Village, Chaguanas, Trinidad and Tobago. E-mail: jjsingh2005@yahoo.com 'bulk' of our excrement so that elimination or 'passing stool' will be easier.

The prevention of cancer is based upon the fact that the less time the odious substances are in the colon, the less time those said substances would have to disrupt cell functioning and create a situation of confused, deadly, blind, self-serving cells. It is now well-known that fibre helps to keep blood sugar and insulin at a steady level (sugar can also be carcinogenic) and satisfies the appetite. Fibre also helps the body to produce substances that control the growth of cells in the lining of the colon. It is well-known by researchers that unregulated growth of cells can lead to cancer (2).

Fibre also collects and holds bile acids. Acids that run loose, even if they are good for digestion, can wreak havoc in our bodies. Soluble fibre also helps to lower cholesterol. The accumulation of cholesterol results in clogging of the arteries which in turn results in heart disease. With direct reference to our food intake, it is now known that apples are fruits filled with soluble fibre and that vegetables "pack a good punch" when it comes to battling with cancer. The flavonoids that apples contain are known to have a high ORAC ie oxygen radical absorbance capacity value. Apples also help our bodies to increase their absorbance of oxygen radicals. Apples have been shown to have potassium which assists in regulating our water balance, levels of acidity, blood pressure and the neuro-muscular function of our bodies. They also play an equally important role in the transmission of electrical impulses in the heart.

The 'forbidden fruit' apple also contains boron which, according to one study, may assist in keeping the beneficial effects of oestrogen during menopause. Other schools of thought suggest that it is helpful against arthritis because it helps to build and maintain healthy bones and teeth by carrying calcium to the bony tissue. Of equal significance is the fact that Ayurvedic medical traditions postulate that the body is a powerful entity and that the apple is akin to a catalyst that triggers the body's built-in protective mechanism. In order for the body's 'land' to be an effective repellent of the cancer 'seed', we must learn more about the effects of 'agni', 'ama' and 'ojas' as we continue to battle with the onslaught of cancer.

\section{VEGETARIAN LIFESTYLE}

The leading question might now be, "How do we get the most of our meals?" Getting the most of our meals focusses primarily on the importance of phytochemicals in fruits and vegeta- 
bles. Most nutritionists know that "veggies have the punch when fighting with cancer". It has also been reported that vegetables are like 'meat blockers' in our diet and that vegetarians tend to live longer, healthier lives. Ongoing research shows that consuming a lot of red meat results in the same damage to the colon as smoking reportedly does due to the presence of cancer-promoting chemicals in both.

\section{Nutritional secrets of the Seventh-day Adventists}

Research is increasingly showing that since Seventh-day Adventists habitually follow a strict diet coupled to a controlled lifestyle, they live comparatively longer and disease-free lives. I followed the dietary habits and lifestyle of an Adventist family that I was familiar with in Trinidad from 1966 to 2000 and my last set of information was that one of the senior members of the said family who was in her eighties, was still walking from door-to-door while "sharing God's word" with fellow villagers. Up to that time, she was reportedly disease-free, and she was still in the habit of sewing and mending her own clothes without the use of prescription eyeglasses.

The aforementioned group of people firmly believe that a diet of fibre binds carcinogens and renders them harmless. In addition, vegetables such as cabbage, broccoli, mustard greens, cauliflower, Brussels sprouts, kale and the ever-popular Chinese bok choy contain 'indoles' which reportedly prevent toxins from damaging DNA. They also reportedly block or prevent the effectiveness of oestrogen and as such, they are quite effective in fighting cancer (3).
Of equal importance is the fact that in order to get the most from our meals - whether cooked or freshly-picked - we must consume liberal amounts of leafy vegetables, garlic, onion, grains and tomatoes, while not forgetting the anti-tumour properties of turmeric. It is now well-known that turmeric has been used by East Indians for more than 5000 years. They have generally lived a relatively stress-free life and maintained a relatively meat-free diet with a timeframe of three hours between meals and the heaviest meal of the day being at midday. As a participant-observer, I am able to state that most East Indian families that I have studied in Trinidad and Tobago live a family-oriented life, work hard and eat nutritious foods, all in an atmosphere of happiness which is undoubtedly a digestive aid (4).

Above all, no amount of 'safe' foods will protect us from cancer if we continue to house negative thoughts, pursue unrealistic goals and not sincerely believe in the power of God's healing.

\section{REFERENCES}

1. Chopra A, Doiphode VV. Ayurvedic medicine. Core concept, therapeutic principles, and current relevance. Med Clin North Am 2002; 86: 7589 , vii.

2. Health.com. 5 everyday foods to fight cancer [Internet]. Health Media Ventures, Inc; ${ }^{2014}$. Available from: www.health.com/health/ gallery $/ 0,20689132,00 \cdot h t m l$

3. Nutrition411.Seventh-Day Adventist diet [Internet]. Nutrition411; ${ }^{\circledR} 2014$. Available from: www.nutrition411.com/education-materials/allergiesintolerances-and-special-diets/item/1458-seventh-day-adventist-diet

4. Gogtay NJ, Bhatt HA, Dalvi SS, Kshirsagar NA. The use and safety of non-allopathic Indian medicines. Drug Saf 2002; 25: 1005-19. 